\title{
Perforin-Like Proteins of Apicomplexan Parasites
}

\author{
Juliane Sassmannshausen, Gabriele Pradel and Sandra Bennink* \\ Division of Cellular and Applied Infection Biology, Institute of Zoology, Rheinisch-Westfälische Technische Hochschule Aachen \\ University, Aachen, Germany
}

\section{OPEN ACCESS}

Edited by:

Kai Matuschewski,

Humboldt University of

Berlin, Germany

Reviewed by:

Elena Deligianni,

Foundation of Research and

Technology (FORTH), Greece

Chris J. Janse,

Leiden University Medical

Center, Netherlands

*Correspondence:

Sandra Bennink

bennink@bio2.rwth-aachen.de

Specialty section:

This article was submitted to

Parasite and Host,

a section of the journal

Frontiers in Cellular and Infection

Microbiology

Received: 01 July 2020

Accepted: 13 August 2020

Published: 15 September 2020

Citation:

Sassmannshausen J, Pradel G and

Bennink S (2020) Perforin-Like

Proteins of Apicomplexan Parasites.

Front. Cell. Infect. Microbiol. 10:578883.

doi: 10.3389/fcimb.2020.578883
Perforins are secreted proteins of eukaryotes, which possess a membrane attack complex/perforin (MACPF) domain enabling them to form pores in the membranes of target cells. In higher eukaryotes, they are assigned to immune defense mechanisms required to kill invading microbes or infected cells. Perforin-like proteins (PLPS) are also found in apicomplexan parasites. Here they play diverse roles during lifecycle progression of the intracellularly replicating protozoans. The apicomplexan PLPS are best studied in Plasmodium and Toxoplasma, the causative agents of malaria and toxoplasmosis, respectively. The PLPs are expressed in the different lifecycle stages of the pathogens and can target and lyse a variety of cell membranes of the invertebrate and mammalian hosts. The PLPs thereby either function in host cell destruction during exit or in overcoming epithelial barriers during tissue passage. In this review, we summarize the various PLPs known for apicomplexan parasites and highlight their roles in Plasmodium and Toxoplasma lifecycle progression.

\section{Keywords: apicomplexa, Plasmodium falciparum, malaria, Toxoplasma gondii, perforin, MACPF domain, host cell egress, cell traversal}

\section{INTRODUCTION}

Members of the pore-forming Membrane Attack Complex/Perforin (MACPF) superfamily are highly conserved in both prokaryotes and eukaryotes, and are mainly used for immune defense or virulence. During the co-evolution of pathogens and hosts, both have developed pore-forming proteins facilitating target membrane lysis and translocation of molecules.

Eukaryotic parasites of the phylum Apicomplexa express MACPF domain-containing proteins termed perforin-like proteins (PLPs). The Apicomplexa comprises a diverse group of intracellularly replicating protozoans that share the apical complex, composed of secretory organelles, such as the micronemes and rhoptries-and structural elements. Calcium-regulated protein discharge from the micronemes is fundamental to motility, cell invasion and egress of apicomplexan parasites (e.g., reviewed in Blackman and Bannister, 2001; Dubois and Soldati-Favre, 2019). Members of the phylum Apicomplexa include parasites that can cause infectious diseases relevant to human or veterinary medicine, such as the malaria parasite Plasmodium or representatives of the genera Toxoplasma, Babesia, and Eimeria.

Many apicomplexan parasites exhibit complex lifecycles, during which they reproduce both asexually and sexually, and which include one or more hosts. For example, the malaria parasite Plasmodium is transmitted from human to human via the bite of an Anopheles mosquito, which serves as the definitive host. The parasite Toxoplasma gondii on the other hand infects members of the family Felidae (domestic cats and their relatives) as its definitive host, but can use other vertebrates as intermediate hosts. Lifecycle progression of apicomplexan parasites is highly dependent on host cell traversal as well as invasion of and egress from host cells. 
We here review the role of apicomplexan PLPs (ApiPLPs) during lifecycle progression, with special focus on the processes of cell traversal and host cell egress. As most work about ApiPLPs has been done on Plasmodium and T. gondii, we will concentrate on these species as representatives.

\section{CONSERVATION OF APICOMPLEXAN MACPF PROTEINS}

The MACPF superfamily is named after the central protein domain shared by the membrane attack complex (MAC) proteins of the human complement system (C6, C7, C8 $\alpha, \mathrm{C} 8 \beta$, and $\mathrm{C} 9$ ) and the cytolytic perforin (PF) of cytotoxic $\mathrm{T}$ lymphocytes and natural killer cells. However, members of the superfamily can be found in all three domains of life, i.e., eubacteria, archaebacteria, and eukaryotes (Moreno-Hagelsieb et al., 2017). In eukaryotes, they are not only involved in immune defense mechanisms, but additionally play important roles in various biological processes, such as embryonic development or neural migration (reviewed in Lukoyanova et al., 2016).

Among the phylum of Apicomplexa, which almost exclusively comprises obligatory intracellular parasites, MACPF domaincontaining proteins are encoded in all genomes sequenced so far, except for Cryptosporidium, which might have lost the genes during evolution. The number of MACPF proteins however varies between the different species, which might be linked to the degree of lifecycle complexity (see Table 1). In general, parasites that are transmitted to vertebrates via insects, such as Plasmodium, Theileria, or Babesia, seem to express more PLPs than parasites, which are restricted to vertebrates, e.g., Toxoplasma, Neospora, or Eimeria. While Plasmodium parasites express five and Theileria and Babesia six to nine PLPs, Toxoplasma, Neospora, and Eimeria only express two to three PLPs.

\section{DOMAIN ARCHITECTURE AND MECHANISM OF PORE FORMATION}

The apicomplexan PLPs characterized so far share the basic architecture of canonical MACPF proteins but additionally exhibit some unique features. They are composed of a central MACPF domain, surrounded by a variable $\mathrm{N}$-terminal region and an apicomplexan-specific $\beta$-pleated sheet-rich C-terminal region (reviewed in Kafsack and Carruthers, 2010). The Nterminal region does not only vary in length and sequence between different apicomplexan PLPs (see Figure 1), but also between proteins of the same species. For example the two MACPF-domain containing proteins that are expressed in $T$. gondii, TgPLP1, and TgPLP2, only share $13 \%$ sequence identity in the $\mathrm{N}$-terminal regions, while the $\mathrm{C}$-terminal regions are $36 \%$ identical.

The canonical MACPF domain, which is structurally similar to prokaryotic cholesterol-dependent cytolysins (CDCs), consists of a central four-stranded $\beta$-sheet that is flanked by two $\alpha$ helical clusters (Hadders et al., 2007; Rosado et al., 2007). The $\alpha$-helical clusters display the typical pattern of alternating hydrophilic and hydrophobic amino acids and convert into amphipathic transmembrane $\beta$-hairpins during pore-formation (Shepard et al., 1998; Shatursky et al., 1999; reviewed in Tweten, 2005; Law et al., 2010; Aleshin et al., 2012). Interestingly, Theileria and Babesia are predicted to encode PLPs that comprise more than one MACPF domain (see Figure 1 and Table 1), which might enable pore-formation using a reduced number of monomers. Further, the MACPF domains of ApiPLPs exhibit several unique characteristics that are absent in canonical MACPF domains. They consist of a pair of anti-parallel $\alpha$ helices and two pairs of cysteine residues, which are presumably responsible for stabilization. While the first pair is thought to stabilize the unique anti-parallel $\alpha$-helices in the MACPF domain, the second one might support two strands of the central $\beta$-sheet (reviewed in Kafsack and Carruthers, 2010). The Cterminal regions of ApiPLPs contain a $\beta$-sheet-rich domain, called APC- $\beta$ (ApiPLP C-terminal $\beta$-pleated sheet) domain, unique to the Apicomplexa, which is probably necessary for initial binding to the target membrane. Analyses of the T. gondii PLP TgPLP1 revealed that both, the N-terminal domain as well as the $\mathrm{C}$-terminal domain, have membrane-binding activity, as shown in membrane flotation experiments with recombinant $\mathrm{N}$ - and C-terminal domains of the protein. However, Roiko and Carruthers (2013) demonstrated that only the C-terminal domain is critical for protein function. The authors generated several domain deletion strains expressing separate domains or domain combinations of the protein and subjected them to lysis assays, PVM permeabilization experiments and mouse virulence assays. In these experiments, parasites expressing the MACPF domain and C-terminal region of TgPLP1 mostly behaved like the wildtype, whereas parasites lacking one of these domains had no TgPLP1 activity (Roiko and Carruthers, 2013).

Recently published crystal structures of purified APC- $\beta$ domains of TgPLP1 gave insight into the architecture and membrane-binding properties of ApiPLPs (Guerra et al., 2018; Ni et al., 2018). The studies revealed that the TgPLP1 APC- $\beta$ domain has an unusual $\beta$-prism fold comprising three subdomains. One of these subdomains exhibits a protruding hydrophobic loop tipped by an exposed tryptophan that is presumably responsible for membrane insertion upon binding (Guerra et al., 2018; Ni et al., 2018). Accordingly, mutant parasites expressing TgPLP1 with a loop that is either shortened or changed in amino acid identity or hydrophobicity display an impaired egress phenotype recapitulating the TgPLP1-knock out phenotype, including the formation of smaller plaques compared to wildtype parasites, impaired PVM rupture and delayed egress as determined via LDH activity measurement in culture supernatants (see below; Kafsack et al., 2009; Guerra et al., 2018).

Successful pore formation by perforin-like proteins relies on several consecutive steps and begins with the release of soluble monomers that bind to their target membrane typically via their C-terminal domain. Oligomerization of PLP monomers by lateral interactions results in the formation of a ring-like structure, the so-called pre-pore that is not yet fully inserted into the membrane. Only after conformational rearrangement of the MACPF domain, during which the two $\alpha$-helical clusters transform into transmembrane $\beta$-hairpins, a 
TABLE 1 | Putative apicomplexan PLPs with their gene identification numbers according to EuPathDB.org (Aurrecoechea et al., 2017), molecular weight (MW), peak expression of the plasmodial genes (López-Barragán et al., 2011; Otto et al., 2014), and function.

\begin{tabular}{|c|c|c|c|c|c|}
\hline Organism & $\begin{array}{l}\text { GeneID EuPathDB and } \\
\text { protein name }\end{array}$ & $\begin{array}{c}\text { MW } \\
\text { (kDa) }\end{array}$ & $\begin{array}{l}\text { Peak } \\
\text { expression }\end{array}$ & Function & References \\
\hline \multirow[t]{5}{*}{$\begin{array}{l}\text { Plasmodium } \\
\text { falciparum }\end{array}$} & $\begin{array}{l}\text { PF3D7_0408700 } \\
\text { (PPLP1) }\end{array}$ & 94 & GC & $\begin{array}{l}\text { Traversal of human cells (sporozoite); Host } \\
\text { cell egress (merozoite) }\end{array}$ & $\begin{array}{l}\text { Garg et al., 2013; Yang et al., } \\
2017\end{array}$ \\
\hline & $\begin{array}{l}\text { PF3D7_1216700 } \\
\text { (PPLP2) }\end{array}$ & 124 & OK & Host cell egress (gametocyte) & $\begin{array}{l}\text { Wirth et al., 2014; Hentzschel } \\
\text { et al., } 2020\end{array}$ \\
\hline & $\begin{array}{l}\text { PF3D7_0923300 } \\
\text { (PPLP3) }\end{array}$ & 93 & OK & & \\
\hline & $\begin{array}{l}\text { PF3D7_0819400 } \\
\text { (PPLP4) }\end{array}$ & 76 & OK & $\begin{array}{l}\text { Traversal of mosquito midgut epithelium } \\
\text { (ookinete) }\end{array}$ & Wirth et al., 2015 \\
\hline & $\begin{array}{l}\text { PF3D7_0819200 } \\
\text { (PPLP5) }\end{array}$ & 79 & OK & & \\
\hline \multirow[t]{5}{*}{$\begin{array}{l}\text { Plasmodium } \\
\text { berghei }\end{array}$} & $\begin{array}{l}\text { PBANKA_1006300 } \\
\text { (PPLP1) }\end{array}$ & 90 & OK & $\begin{array}{l}\text { Traversal of sinusoidal endothelium } \\
\text { (sporozoite) }\end{array}$ & Ishino et al., 2005 \\
\hline & $\begin{array}{l}\text { PBANKA_1432400 } \\
\text { (PPLP2) }\end{array}$ & 114 & GC & Host cell egress (gametocyte) & Deligianni et al., 2013 \\
\hline & $\begin{array}{l}\text { PBANKA_0824200 } \\
\text { (PPLP3) }\end{array}$ & 92 & GC, OK & $\begin{array}{l}\text { Traversal of mosquito midgut epithelium } \\
\text { (ookinete) }\end{array}$ & Kadota et al., 2004 \\
\hline & $\begin{array}{l}\text { PBANKA_0711400 } \\
\text { (PPLP4) }\end{array}$ & 79 & OK & $\begin{array}{l}\text { Traversal of mosquito midgut epithelium } \\
\text { (ookinete) }\end{array}$ & Deligianni et al., 2018 \\
\hline & $\begin{array}{l}\text { PBANKA_0711600 } \\
\text { (PPLP5) }\end{array}$ & 80 & OK & $\begin{array}{l}\text { Traversal of mosquito midgut epithelium } \\
\text { (ookinete) }\end{array}$ & Ecker et al., 2007 \\
\hline \multirow[t]{2}{*}{ Toxoplasma gondii } & TGME49_204130 (TgPLP1) & 125 & & Vacuolar and host cell egress (tachyzoite) & $\begin{array}{l}\text { Kafsack et al., 2009; Roiko and } \\
\text { Carruthers, 2013; Guerra et al., } \\
2018\end{array}$ \\
\hline & TGME49_272430 (TgPLP2) & 92 & & & \\
\hline \multirow[t]{7}{*}{ Theileria annulata } & TA19210 & 126 & & & \\
\hline & TA11680 & 92 & & & \\
\hline & TA07905 & 57 & & & \\
\hline & TA07910 & 67 & & & \\
\hline & TA18285 & 140 & & & \\
\hline & TA18325 & 39 & & & \\
\hline & TA14315 & 13 & & & \\
\hline \multirow[t]{7}{*}{ Babesia bovis } & BBOV_IV001370 & 108 & & & \\
\hline & BBOV_II007150 & 84 & & & \\
\hline & BBOV_III000410a & 143 & & & \\
\hline & BBOV_II002020 & 46 & & & \\
\hline & BBOV_II001970 & 61 & & & \\
\hline & BBOV_III000320 & 56 & & & \\
\hline & BBOV_II006750 & 45 & & & \\
\hline \multirow{3}{*}{$\begin{array}{l}\text { Neospora } \\
\text { caninum }\end{array}$} & NCLIV_020990 & 114 & & & \\
\hline & NCLIV_034870 & 95 & & & \\
\hline & NCLIV_035170 & 151 & & & \\
\hline \multirow[t]{2}{*}{ Eimeria tenella } & ETH_00005740 & 83 & & & \\
\hline & ETH_00025550 & 148 & & & \\
\hline
\end{tabular}

GC, gametocyte; OK, ookinete.

a Three MACPF domains predicted.

$\beta$-barrel pore is formed that finally inserts into the target membrane (Shepard et al., 1998, 2000; Shatursky et al., 1999; Law et al., 2010; Lukoyanova et al., 2015). MACPF pores are typically between 80 and $200 \AA$ in diameter and contain 13-20 monomers (reviewed in Pipkin and Lieberman, 2007; Rosado et al., 2007; Lukoyanova et al., 2015). Although gel analyses of TgPLP1 complexes indicated the presence of more than 20 monomers comprising the pore complex (Roiko and Carruthers, 2013), recent crystallographic studies suggested that the TgPLP1 MACPF domain forms rather small, hexameric assemblies (Ni et al., 2018).

In order to ensure membrane specificity, the pore-forming process has to be tightly controlled. Mechanisms to avoid lysis of non-target membranes have been best studied for the 


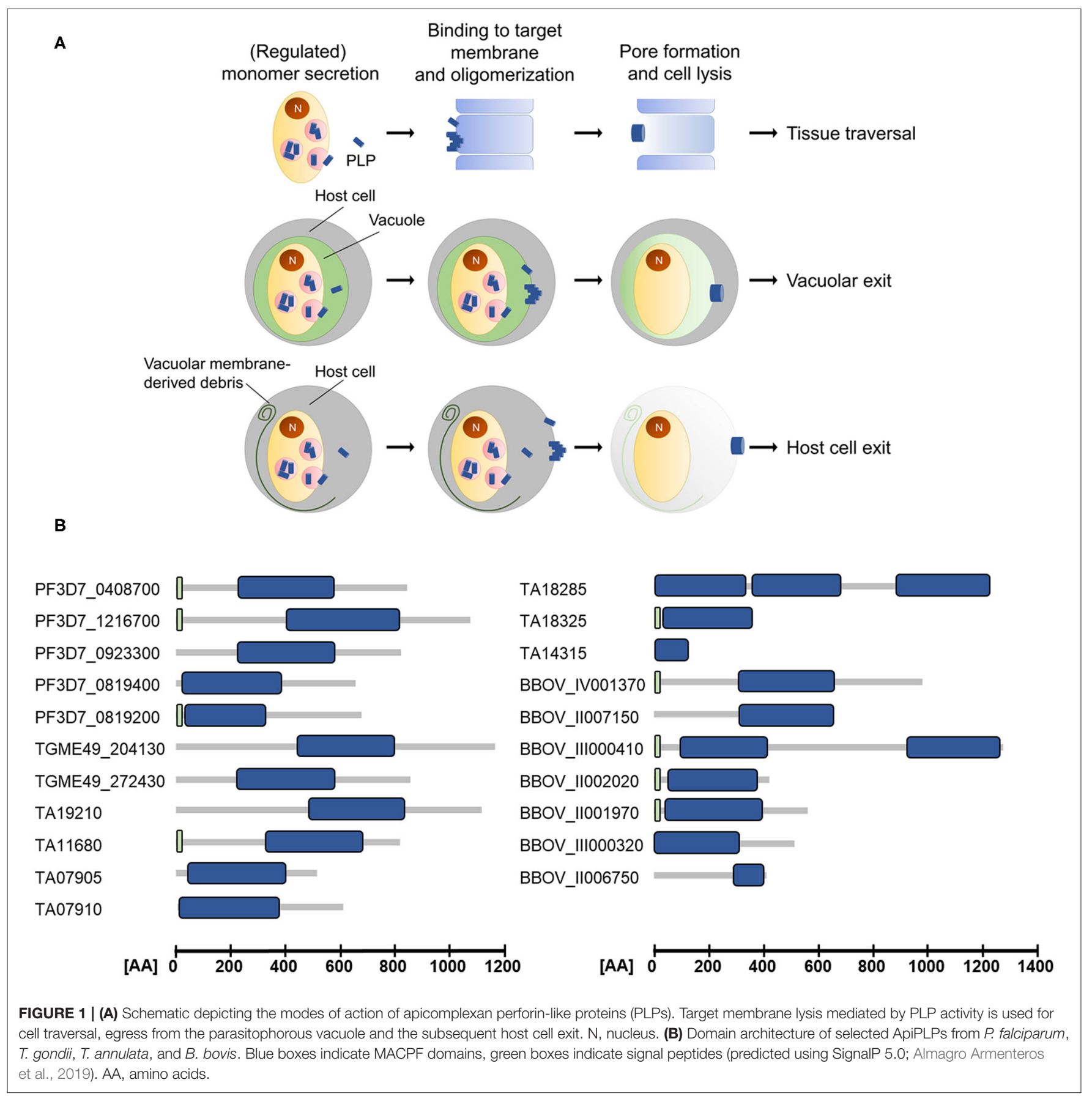

pore-formation by human immune molecules, such as perforins and members of the complement system, but potentially also apply for the pore-formation by apicomplexan PLPs. These mechanisms might include the binding to an inhibitor protein prior to the lytic function of the PLP, regulated secretion, $\mathrm{pH}$-dependent activity, protease-mediated activation or the interaction with specific phospholipids in the target membranes, as it has been shown for TgPLP1 (see below). Non-target membranes might further be protected from lysis through the presence of inhibitor proteins as it has been shown in humans as a mechanism to avoid self-cell destruction by the complement system (e.g., reviewed in Pipkin and Lieberman, 2007; Kafsack and Carruthers, 2010; Meri, 2016).

\section{APICOMPLEXAN PERFORINS IN HOST CELL EGRESS}

PLPs are involved in the exit of apicomplexan parasites from their respective host cells and hence have important roles for parasite propagation. Apicomplexan parasites mainly egress from their host cells by active lysis of the surrounding membranes, 
the parasitophorous vacuole membrane (PVM), and the host cell membrane (HCM). Host cell exit follows a strictly regulated programme, during which rupture of the PVM precedes HCM breakdown (the so-called inside-out egress). Both steps may involve lytic PLPs (Figure 1). The involvement of PLPs in host cell lysis, however, has so far only been shown experimentally for Toxoplasma and Plasmodium parasites (reviewed in Kafsack and Carruthers, 2010; Wirth and Pradel, 2012; Flieger et al., 2018).

Of the two PLPs detected in T. gondii, only TgPLP1 hitherto showed a clear involvement in host cell exit (Kafsack et al., 2009; Roiko and Carruthers, 2013; Guerra et al., 2018). TgPLP1 localizes to the micronemes of tachyzoites and is secreted in a calcium-dependent manner during egress similar to other micronemal proteins. Parasites lacking TgPLP1 remain enclosed by the PVM and the HCM, demonstrating its role in lysis of these membranes (Kafsack et al., 2009; Roiko and Carruthers, 2013). Before egress, cytosolic calcium concentrations are suppressed by the activity of a protein kinase A (PKA) and T. gondii tachyzoites impaired in PKA signaling spontaneously egress from their host cells in a TgPLP1-dependent fashion (Uboldi et al., 2018). However, it is not yet known if PKA directly regulates TgPLP1 secretion and activity or if they are part of two different pathways that are required for parasite egress.

It is postulated that the egress of $T$. gondii tachyzoites from the host cell is dependent on PV acidification, which promotes membrane binding of TgPLP1 (Roiko et al., 2014). TgPLP1 activity appears to be further regulated by interaction with specific phospholipids located in the respective membrane, particularly phosphatidylethanolamine (PE) or phosphatidylserine (PS), which are characteristic components of the inner leaflet of the red blood cell membrane. The availability of PE and PS, e.g., during egress, increases TgPLP1 activity, whereas the absence of these preferred phospholipid receptors in the outer leaflet of the target cell, e.g., during cell invasion, strongly limits the activity of TgPLP1 (Guerra et al., 2018). In a first model of tachyzoite egress, it has been postulated that TgPLP1 is transported to the PV after secretion, where it interacts with the PVM. This interaction triggers the lytic activity of the protein. After dissolution of the PVM, TgPLP1 binds to phospholipids of the HCM and, hence, further lyses this membrane, in consequence facilitating the final exit of the parasite from its host cell (Guerra et al., 2018).

Active host cell lysis by membrane breaching is also a typical mechanism used by the Plasmodium blood stages during exit from the red blood cell (RBC) (reviewed in Wirth and Pradel, 2012; Flieger et al., 2018). Two types of blood stages actively destroy the enveloping $\mathrm{RBC}$ during egress, the merozoites and the gametocytes, and for both stages, the involvement of plasmodial PLPs (PPLPs) has been reported. Like for T. gondii, egress of Plasmodium from the host cell is mediated by a signaling cascade that involves the sequential activation of a PKG by cGMP and of CDPKs by increased cytosolic calcium and this process results in the discharge of vesicles important for $\mathrm{RBC}$ lysis (reviewed in Flieger et al., 2018). While five PPLPs (termed PPLP1 to PPLP5) are encoded in the Plasmodium genome, only for PPLP1 and PPLP2, an involvement in RBC egress was hitherto shown (Kaiser et al., 2004; Deligianni et al., 2013; Garg et al., 2013; Wirth et al., 2014).
In $P$. falciparum, PPLP1 expression starts in the trophozoite stage and peaks in the mature schizont, where it initially localizes to the micronemes of the merozoites. Similar to TgPLP1, PPLP1 is secreted by the micronemes in a calciumdependent fashion at the onset of RBC egress (Garg et al., 2013). Later, PPLP1 localizes to the PVM and RBC membrane (RBCM). Since recombinant PPLP1 demonstrates membranelytic activities, a role in membrane rupture during merozoite egress from the RBC was postulated. In this context, inhibition of the type-2 phosphatic acid phosphatase PAP2 of $P$. falciparum by propranolol results in the early microneme secretion of PPLP1 by merozoites and in consequence RBCM lysis (Kumar Sah et al., 2019). In general, PAP $2 s$ are able to phosphorylate diacylglycerol to generate phosphatidic acid, the latter of which was previously shown to be crucial for triggering microneme secretion in $T$. gondii tachyzoites (Bullen et al., 2016).

PPLP2 is involved in RBC lysis during egress of the Plasmodium gametocytes at the onset of gametogenesis (Deligianni et al., 2013; Wirth et al., 2014). In gametocytes, PPLP2 localizes to distinct vesicles which probably represent specialized egress vesicles presumably containing further egress-related molecules. Interestingly, these PPLP2-harboring vesicles are negative for the protein G377 which is a known component of osmiophilic bodies (OBs) (Wirth et al., 2014). OBs constitute vesicles of mature gametocytes that release their content into the PV lumen during the first minutes after gametocyte activation. They contain a variety of proteins, e.g., G377, MDV-1/Peg3, GEST, and several proteases, which are probably involved in PVM rupture (reviewed in Flieger et al., 2018). In a subsequent step, PPLP2 is discharged from the second type of vesicles in a calcium-dependent process. In accord with these data, PPLP2 was found to be a component of the P. berghei gametocyte egressome (Kehrer et al., 2016). In both $P$. berghei and P. falciparum, activated gametocytes deficient of PPLP2 remain trapped in the host RBCs (Deligianni et al., 2013; Wirth et al., 2014; Hentzschel et al., 2020). While the PVM ruptures normally, lack of PPLP2 leads to impaired perforation of the $\mathrm{RBC}$ membrane, which is essential to release the erythrocyte cytoplasm prior to the final rupture of the RBCM. In agreement with these data, recombinant PPLP2 was shown to form pores in RBCMs leading to hemoglobin release (Garg et al., 2020; this issue). The recombinant protein was further able to induce senescence in bystander RBCs. The lytic activity of recombinant PPLP2 could be blocked by specific MACPF domain inhibitors, suggesting that the plasmodial perforins may represent targets for future antimalarials.

\section{APICOMPLEXAN PERFORINS IN TISSUE TRAVERSAL}

The PPLPs of Plasmodium are further crucial for tissue traversal during lifecycle progression of the parasite (Figure 1). With the exception of PPLP2, all of the PPLPs were shown to be involved in crossing of epithelial barriers.

The passage through host cell epithelia is particularly important for the infective sporozoites during their journey to the human liver. An initial study on $P$. berghei demonstrated 
that PPLP1 (originally termed SPECT2) is present in sporozoite micronemes and secreted, when these traverse the sinusoidal endothelium (Ishino et al., 2005). Crossing of cells lining capillaries and the subsequent traversal of hepatocytes is a mandatory step of sporozoites, before these are able to settle down in a host hepatocyte to initiate replication (Mota et al., 2001, 2002; Pradel and Frevert, 2001; Amino et al., 2008; Tavares et al., 2013). P. berghei sporozoites deficient of PPLP1 remain in the blood circulation and are unable to establish an infection in mice (Ishino et al., 2005). Similarly, PPLP1-deficient $P$. falciparum sporozoites could not initiate an infection in the humanized mouse model (Yang et al., 2017). A subsequent study on the rodent malaria parasite $P$. yoelii showed that sporozoites traverse cell barriers via a transient vacuole, which is independent of moving junction formation, and that the sporozoites escape this vacuole with the help of PPLP1 (Risco-Castillo et al., 2015). The final invasion of hepatocytes requires a moving junctiondependent PV formation, in which the parasite in then able to grow.

Another epithelial crossing occurs during exit of the mosquito midgut by the motile Plasmodium ookinetes. In P. berghei, PPLP3 (originally termed MAOP), PPLP4 and PPLP5 were shown to be essential for the traversal of the mosquito midgut epithelium by ookinetes, while in P. falciparum, only PPLP4 has been attributed a role in this process so far (Kadota et al., 2004; Ecker et al., 2007; Wirth et al., 2015; Deligianni et al., 2018). Ookinetes lacking any of the three PPLPs are unable to infect female Anopheles mosquitoes. Interestingly, while in $P$. falciparum, PPLP4 is initially expressed in female gametocytes and later localizes to the ookinete micronemes, in P. berghei, PPLP4 was reported to be present on the entire surface of the ookinete (Wirth et al., 2015; Deligianni et al., 2018). While these data demonstrate a crucial role for PPLP3, PPLP4, and PPLP5 in the mosquito-specific lifecycle phase of the malaria parasite, the

\section{REFERENCES}

Aleshin, A. E., Schraufstatter, I. U., Stec, B., Bankston, L. A., Liddington, R. C., and DiScipio, R. G. (2012). Structure of complement C6 suggests a mechanism for initiation and unidirectional, sequential assembly of membrane attack complex (MAC). J. Biol. Chem. 287, 10210-10222. doi: 10.1074/jbc.M111.327809

Almagro Armenteros, J. J., Tsirigos, K. D., Sønderby, C. K., Petersen, T. N., Winther, O., Brunak, S., et al. (2019). SignalP 5.0 improves signal peptide predictions using deep neural networks. Nat. Biotechnol. 37, 420-423. doi: 10.1038/s41587-019-0036-z

Amino, R., Giovannini, D., Thiberge, S., Gueirard, P., Boisson, B., Dubremetz, J. F., et al. (2008). Host cell traversal is important for progression of the malaria parasite through the dermis to the liver. Cell Host Microbe 3, 88-96. doi: 10.1016/j.chom.2007.12.007

Aurrecoechea, C., Barreto, A., Basenko, E. Y., Brestelli, J., Brunk, B. P., Cade, S., et al. (2017). EuPathDB: the eukaryotic pathogen genomics database resource. Nucleic Acids Res. 45, D581-D591. doi: 10.1093/nar/gkw1105

Blackman, M. J., and Bannister, L. H. (2001). Apical organelles of apicomplexa: biology and isolation by subcellular fractionation. Mol. Biochem. Parasitol. 117, 11-25. doi: 10.1016/S0166-6851(01)00328-0

Bullen, H. E., Jia, Y., Yamaryo-Bott,é, Y., Bisio, H., Zhang, O., Jemelin, N. K., et al. (2016). Phosphatidic acid-mediated signaling regulates microneme secretion in toxoplasma. Cell Host Microbe 19, 349-360. doi: 10.1016/j.chom.2016.02.006

Deligianni, E., Morgan, R. N., Bertuccini, L., Wirth, C. C., Silmon de Monerri, N. C., Spanos, L., et al. (2013). A perforin-like protein mediates disruption of the detailed mode of action and any potential synergistic interplay of the three perforins during mosquito midgut traversal still needs to be elucidated.

\section{CONCLUSION}

Despite an increasing number of publications that shed light on the structure of apicomplexan PLPs and their functions during parasitic lifecycle progression, many questions about their mode of action and regulation remain. For instance, further studies are needed to determine how membrane specificity is achieved. What are the receptors for initial membrane binding and how are non-target membranes protected from lysis? How many monomers are involved in complex formation, and, given the fact that some apicomplexan PLPs are predicted to encode multiple MACPF domains, are less of these monomers necessary to form a pore? Furthermore, the role of the unconserved Nterminal regions of apicomplexan PLPs, which vary in length and sequence, remains to be elucidated. Interestingly, some processes, such as the traversal of epithelial cells of the mosquito midgut by Plasmodium ookinetes involve several different PLPs. The interplay of these proteins and potential co-dependencies will be the focus of further studies.

\section{AUTHOR CONTRIBUTIONS}

JS, GP, and SB wrote the manuscript. All authors contributed to the manuscript and approved the submitted version.

\section{ACKNOWLEDGMENTS}

The authors acknowledge funding by the priority programme SPP1580 of the Deutsche Forschungsgemeinschaft (DFG).

erythrocyte membrane during egress of Plasmodium berghei male gametocytes. Cell. Microbiol. 15, 1438-1455. doi: 10.1111/cmi.12131

Deligianni, E., Silmon de Monerri, N. C., McMillan, P. J., Bertuccini, L., Superti, F., Manola, M., et al. (2018). Essential role of plasmodium perforin-like protein 4 in ookinete midgut passage. PLoS ONE 13:e0201651. doi: 10.1371/journal.pone.0201651

Dubois, D. J., and Soldati-Favre, D. (2019). Biogenesis and secretion of micronemes in Toxoplasma gondii. Cell. Microbiol. 21:e13018. doi: 10.1111/cmi.13018

Ecker, A., Pinto, S. B., Baker, K. W., Kafatos, F. C., and Sinden, R. E. (2007). Plasmodium berghei: plasmodium perforin-like protein 5 is required for mosquito midgut invasion in Anopheles stephensi. Exp. Parasitol. 116, 504-508. doi: 10.1016/j.exppara.2007.01.015

Flieger, A., Frischknecht, F., Häcker, G., Hornef, M. W., and Pradel, G. (2018). Pathways of host cell exit by intracellular pathogens. Microb. Cell 5, 525-544. doi: $10.15698 / \mathrm{mic} 2018.12 .659$

Garg, S., Agarwal, S., Kumar, S., Shams Yazdani, S., Chitnis, C. E., and Singh, S. (2013). Calcium-dependent permeabilization of erythrocytes by a perforin-like protein during egress of malaria parasites. Nat. Commun. 4:1736. doi: $10.1038 /$ ncomms 2725

Garg, S., Shivappagowdar, A., Hada, R. S., Ayana, R., Bathula, C., Sen, S., et al. (2020). Plasmodium perforin-like protein pores on the host cell membrane contribute in its multistage growth and erythrocyte senescence. Front. Cell. Infect. Microbiol. 10:121. doi: 10.3389/fcimb.2020.00121

Guerra, A. J., Zhang, O., Bahr, C. M. E., Huynh, M. H., DelProposto, J., Brown, W. C., et al. (2018). Structural basis of Toxoplasma gondii perforin-like protein 
1 membrane interaction and activity during egress. PLoS Pathog. 14:e1007476. doi: 10.1371/journal.ppat.1007476

Hadders, M. A., Beringer, D. X., and Gros, P. (2007). Structure of C8 $\alpha-$ MACPF reveals mechanism of membrane attack in complement immune defense. Science. 317, 1552-1554. doi: 10.1126/science.1147103

Hentzschel, F., Mitesser, V., Fraschka, S. A. K., Krzikalla, D., Carrillo, E. H., Berkhout, B., et al. (2020). Gene knockdown in malaria parasites via noncanonical RNAi. Nucleic Acids Res. 48:e2. doi: 10.1093/nar/gkz927

Ishino, T., Chinzei, Y., and Yuda, M. (2005). A Plasmodium sporozoite protein with a membrane attack complex domain is required for breaching the liver sinusoidal cell layer prior to hepatocyte infection. Cell. Microbiol. 7, 199-208. doi: 10.1111/j.1462-5822.2004.00447.x

Kadota, K., Ishino, T., Matsuyama, T., Chinzei, Y., and Yuda, M. (2004). Essential role of membrane-attack protein in malarial transmission to mosquito host. Proc. Natl. Acad. Sci. U.S.A. 101, 16310-16315. doi: 10.1073/pnas.0406187101

Kafsack, B. F. C., and Carruthers, V. B. (2010). Apicomplexan perforin-like proteins. Commun. Integr. Biol. 3, 18-23. doi: 10.4161/cib.3.1.9794

Kafsack, B. F. C., Pena, J. D. O., Coppens, I., Ravindran, S., Boothroyd, J. C., and Carruthers, V. B. (2009). Rapid membrane disruption by a perforinlike protein facilitates parasite exit from host cells. Science 323, 530-533. doi: $10.1126 /$ science. 1165740

Kaiser, K., Camargo, N., Coppens, I., Morrisey, J. M., Vaidya, A. B., and Kappe, S. H. I. (2004). A member of a conserved plasmodium protein family with membrane-attack complex/perforin (MACPF)-like domains localizes to the micronemes of sporozoites. Mol. Biochem. Parasitol. 133, 15-26. doi: 10.1016/j.molbiopara.2003.08.009

Kehrer, J., Frischknecht, F., and Mair, G. R. (2016). Proteomic analysis of the plasmodium berghei gametocyte egressome and vesicular bioID of osmiophilic body proteins identifies merozoite TRAP-like protein (MTRAP) as an essential factor for parasite transmission. Mol. Cell. Proteomics 15, 2852-2862. doi: 10.1074/mcp.M116.058263

Kumar Sah, R., Garg, S., Dangi, P., Ponnusamy, K., and Singh, S. (2019). Phosphatidic acid homeostasis regulated by a type- 2 phosphatidic acid phosphatase represents a novel druggable target in malaria intervention. Cell Death Discov. 5:107. doi: 10.1038/s41420-019-0187-1

Law, R. H. P., Lukoyanova, N., Voskoboinik, I., Caradoc-Davies, T. T., Baran, K., Dunstone, M. A., et al. (2010). The structural basis for membrane binding and pore formation by lymphocyte perforin. Nature 468, 447-451. doi: 10.1038/nature09518

López-Barragán, M. J., Lemieux, J., Quiñones, M., Williamson, K. C., Molina-Cruz, A., Cui, K., et al. (2011). Directional gene expression and antisense transcripts in sexual and asexual stages of Plasmodium falciparum. BMC Genomics 12:587. doi: 10.1186/1471-2164-12-587

Lukoyanova, N., Hoogenboom, B. W., and Saibil, H. R. (2016). The membrane attack complex, perforin and cholesteroldependent cytolysin superfamily of pore-forming proteins. J. Cell Sci. 129, 2125-2133. doi: 10.1242/jcs.182741

Lukoyanova, N., Kondos, S. C., Farabella, I., Law, R. H. P., Reboul, C. F., Caradoc-Davies, T. T., et al. (2015). Conformational changes during pore formation by the perforin-related protein pleurotolysin. PLoS Biol. 13:e1002049. doi: 10.1371/journal.pbio.1002049

Meri, S. (2016). Self-nonself discrimination by the complement system. FEBS Lett. 590, 2418-2434. doi: 10.1002/1873-3468.12284

Moreno-Hagelsieb, G., Vitug, B., Medrano-Soto, A., and Saier, M. H. J. (2017). The membrane attack complex/perforin (MACPF) superfamily. J. Mol. Microbiol. Biotechnol. 27, 252-267. doi: 10.1159/000481286

Mota, M. M., Hafalla, J. C. R., and Rodriguez, A. (2002). Migration through host cells activates plasmodium sporozoites for infection. Nat. Med. 8, 1318-1322. doi: $10.1038 / \mathrm{nm} 785$

Mota, M. M., Pradel, G., Vanderberg, J. P., Hafalla, J. C. R., Frevert, U., Nussenzweig, R. S., et al. (2001). Migration of plasmodium sporozoites through cells before infection. Science 291, 141-144. doi: 10.1126/science.291.5501.141

Ni, T., Williams, S. I., Rezelj, S., Anderluh, G., Harlos, K., Stansfeld, P. J., et al. (2018). Structures of monomeric and oligomeric forms of the Toxoplasma gondii perforin-like protein 1. Sci. Adv. 4:eaaq0762. doi: 10.1126/sciadv.aaq0762

Otto, T. D., Böhme, U., Jackson, A. P., Hunt, M., Franke-Fayard, B., Hoeijmakers, W. A. M., et al. (2014). A comprehensive evaluation of rodent malaria parasite genomes and gene expression. BMC Biol. 12:86. doi: 10.1186/s12915-014-0086-0
Pipkin, M. E., and Lieberman, J. (2007). Delivering the kiss of death: progress on understanding how perforin works. Curr. Opin. Immunol. 19, 301-308. doi: 10.1016/j.coi.2007.04.011

Pradel, G., and Frevert, U. (2001). Malaria sporozoites actively enter and pass through rat Kupffer cells prior to hepatocyte invasion. Hepatology 33, 1154-1165. doi: 10.1053/jhep.2001.24237

Risco-Castillo, V., Topcu, S., Marinach, C., Manzoni, G., Bigorgne, A., Briquet, S., et al. (2015). Malaria sporozoites traverse host cells within transient vacuoles. Cell Host Microbe 18, 593-603. doi: 10.1016/j.chom.2015.10.006

Roiko, M. S., and Carruthers, V. B. (2013). Functional dissection of Toxoplasma gondii perforin-like protein 1 reveals a dual domain mode of membrane binding for cytolysis and parasite egress. J. Biol. Chem. 288, 8712-8725. doi: 10.1074/jbc.M113.450932

Roiko, M. S., Svezhova, N., and Carruthers, V. B. (2014). Acidification activates Toxoplasma gondii motility and egress by enhancing protein secretion and cytolytic activity. PLoS Pathog. 10:e1004488. doi: 10.1371/journal.ppat.1004488

Rosado, C. J., Buckle, A. M., Law, R. H. P., Butcher, R. E., Kan, W. T., Bird, C. H., et al. (2007). A common fold mediates vertebrate defense and bacterial attack. Science 317, 1548-1551. doi: 10.1126/science.1144706

Shatursky, O., Heuck, A. P., Shepard, L. A., Rossjohn, J., Parker, M. W., Johnson, A. E., et al. (1999). The mechanism of membrane insertion for a cholesteroldependent cytolysin: a novel paradigm for pore-forming toxins. Cell 99, 293-299. doi: 10.1016/\$0092-8674(00)81660-8

Shepard, L. A., Heuck, A. P., Hamman, B. D., Rossjohn, J., Parker, M. W., Ryan, K. R., et al. (1998). Identification of a membrane-spanning domain of the thiol-activated pore-forming toxin Clostridium perfringens perfringolysin $\mathrm{O}$ : an $\alpha$-helical to $\beta$-sheet transition identified by fluorescence spectroscopy. Biochemistry 37, 14563-14574. doi: 10.1021/bi981452f

Shepard, L. A., Shatursky, O., Johnson, A. E., and Tweten, R. K. (2000). The mechanism of pore assembly for a cholesterol-dependent cytolysin: formation of a large prepore complex precedes the insertion of the transmembrane $\beta$-hairpins. Biochemistry 39, 10284-10293. doi: 10.1021/bi000436r

Tavares, J., Formaglio, P., Thiberge, S., Mordelet, E., Van Rooijen, N., Medvinsky, A., et al. (2013). Role of host cell traversal by the malaria sporozoite during liver infection. J. Exp. Med. 210, 905-915. doi: 10.1084/jem.20121130

Tweten, R. K. (2005). Cholesterol-dependent cytolysins, a family of versatile pore-forming toxins. Infect. Immun. 73, 6199-6209. doi: 10.1128/IAI.73.10.6199-6209.2005

Uboldi, A. D., Wilde, M. L., McRae, E. A., Stewart, R. J., Dagley, L. F., Yang, L., et al. (2018). Protein kinase A negatively regulates $\mathrm{Ca}^{2+}$ signalling in Toxoplasma gondii. PLoS Biol. 16:e2005642. doi: 10.1371/journal.pbio.2005642

Wirth, C. C., Bennink, S., Scheuermayer, M., Fischer, R., and Pradel, G. (2015). Perforin-like protein PPLP4 is crucial for mosquito midgut infection by Plasmodium falciparum. Mol. Biochem. Parasitol. 201, 90-99. doi: 10.1016/j.molbiopara.2015.06.005

Wirth, C. C., Glushakova, S., Scheuermayer, M., Repnik, U., Garg, S., Schaack, D., et al. (2014). Perforin-like protein PPLP2 permeabilizes the red blood cell membrane during egress of Plasmodium falciparum gametocytes. Cell. Microbiol. 16, 709-733. doi: $10.1111 / \mathrm{cmi} .12288$

Wirth, C. C., and Pradel, G. (2012). Molecular mechanisms of host cell egress by malaria parasites. Int. J. Med. Microbiol. 302, 172-178. doi: 10.1016/j.ijmm.2012.07.003

Yang, A. S. P., O’Neill, M. T., Jennison, C., Lopaticki, S., Allison, C. C., Armistead, J. S., et al. (2017). Cell traversal activity is important for Plasmodium falciparum liver infection in humanized mice. Cell Rep. 18, 3105-3116. doi: 10.1016/j.celrep.2017.03.017

Conflict of Interest: The authors declare that the research was conducted in the absence of any commercial or financial relationships that could be construed as a potential conflict of interest.

Copyright (๑) 2020 Sassmannshausen, Pradel and Bennink. This is an open-access article distributed under the terms of the Creative Commons Attribution License (CC $B Y)$. The use, distribution or reproduction in other forums is permitted, provided the original author(s) and the copyright owner(s) are credited and that the original publication in this journal is cited, in accordance with accepted academic practice. No use, distribution or reproduction is permitted which does not comply with these terms. 